\title{
Right ventricular outflow tract stenting in double outlet right ventricle with critical pulmonary stenosis and hypoplastic pulmonary arteries
}

\author{
Ewelina Kwaśniak, Ireneusz Haponiuk, Maciej Chojnicki, Radosław Jaworski, Aneta Szofer-Sendrowska, \\ Mariusz Steffens
}

Department of Pediatric Cardiac Surgery, Mikolaj Kopernik Hospital, Gdansk, Poland

Adv Interv Cardiol 2016; 12, 3 (45): 267-270

DOI: 10.5114/aic.2016.61651

\section{Introduction}

Double outlet right ventricle (DORV) is a congenital heart disease in which the great arteries (aorta and main pulmonary artery) arise from the right ventricle (RV), with concomitant ventricular septal defect (VSD), usually non-restrictive. Double outlet right ventricle can be accompanied by other cardiovascular anomalies, such as ventricular hypoplasia, restrictive septal defects and various pulmonary vascular bed anomalies, including hypoplastic pulmonary arteries (PA).

Critical right ventricle outflow tract (RVOT) stenosis and hypoplasia of pulmonary arteries in newborns with DORV necessitates the need to maintain pulmonary blood flow to provide optimal systemic oxygenation in severely cyanotic newborns. Routinely recommended treatment for cyanotic newborns is a surgical procedure with implantation of a Blalock-Taussig systemic-to-pulmonary artery shunt (BT shunt), or interventional patent arterial duct (PDA) stenting. In complex RVOT stenosis with hypoplastic pulmonary arteries alternative percutaneous multilevel RVOT and pulmonary trunk stenting could serve as an alternative treatment [1, 2].

We report multistage treatment of a hypotrophic infant suffering from DORV with RVOT stenosis and a hypoplastic pulmonary vascular bed. Initial diagnostics with angiography revealed multilevel obstruction of the RVOT with severe hypoplasia of pulmonary arteries. The baby, who presented severe cyanosis, did not meet anatomic criteria for surgical palliation while the ductal flow remained insufficient. Her initial morphology determined our alternative strategy with initial RVOT stenting, despite the hindrance caused by extremely low body weight.

\section{Case report}

The 3-day-old term born hypotrophic neonate was admitted to the Department of Pediatric Cardiac Surgery with the initial diagnosis of tetralogy of Fallot.

The girl was born by normal spontaneous vaginal delivery at the $39^{\text {th }}$ week of gestation with a birth weight of $2370 \mathrm{~g}$. Her prenatal medical history was complicated by maternal heavy nicotinism in pregnancy. Congenital heart disease was diagnosed at the $3^{\text {rd }}$ day of life, and prostaglandin E1 (PGE1) intravenous infusion was administered.

The child was transferred to our department in an emergency setting because of rapid general deterioration with severe cyanosis. Because of hypoxemia and hypercapnia the baby was intubated on admission, and remained on mechanical ventilation during the diagnostics. Also continuous infusion of PGE1 was carried on.

Transthoracic echocardiogram (TTE) performed on admission revealed DORV with a large subaortic ventricular septal defect. There was $70-80 \%$ dextroposition of the wide aorta with mild aortic valve insufficiency, and a severely hypertrophied right ventricle with right ventricle outlet tract obstruction (RVOTO). Pulmonary valve stenosis (pulmonary valve annulus diameter of $3 \mathrm{~mm}$ ) was present with evidence of a right ventricle - main pulmonary artery pressure gradient of $65 \mathrm{~mm} \mathrm{Hg}$. The main pulmonary artery (MPA) was severely hypoplastic through its entire length. The MPA inner diameter was $3.5 \mathrm{~mm}$. Continuous $2 \mathrm{~mm}$ diameter left and right pulmonary arteries (LPA and RPA) were seen. There was no echocardiographic pattern of PDA flow; thus the infusion of PGE1 was stopped.

\section{Corresponding author:}

Ewelina Kwaśniak MD, Department of Pediatric Cardiac Surgery, Mikolaj Kopernik Hospital, 1-6 Nowe Ogrody St, 80-803 Gdansk, Poland, phone: +48604661865 , e-mail: ekwasnia@wp.pl

Received: 17.09.2015, accepted: 21.10.2015. 
The newborn was referred for an emergency percutaneous balloon angioplasty of the right ventricle outflow tract obstruction (RVOTO). The procedure was performed under general anesthesia. Hypoplasia of the MPA and pulmonary bed with a small diameter of the right and left pulmonary arteries was noted. The initial McGoon index was 0.8

Nevertheless an increase of peripheral saturation was observed after percutaneous angioplasty of the RVOT. The child was extubated and subsequently discharged from the reference department of pediatric cardiology.

After 3 weeks the patient was admitted again because of general deterioration, decrease of saturation (65-70\%) and fatigue during oral feeding, which required nasogastric tube feeding. The infant was referred for repeated percutaneous balloon RVOT angioplasty. During the procedure the symptoms of early restenosis were observed; thus 2 vascular stents were directly implanted following telescope stent-in-stent technique in the area of the RVOT and MPA (Abbott Vascular MULTI-LINK, $4 \times$ $8 \mathrm{~mm}$ and $3.5 \times 15 \mathrm{~mm}$, Figure 1). After the procedure the patient's general condition improved. The increase of blood oxygen saturation and concomitant decrease of RV-MPA pressure gradient in control echocardiography were noted. The anticoagulation protocol with initial heparin infusion $(15 \mathrm{mg} / \mathrm{kg} \mathrm{bw} / \mathrm{h})$ followed by chronic oral aspirin administration ( $3 \mathrm{mg} / \mathrm{kg}$ bw) was continued.

In the $10^{\text {th }}$ week of life percutaneous balloon RVOT stent redilatation was attempted. The findings of right ventricle hypertrophy, persistent blood flow from RV to

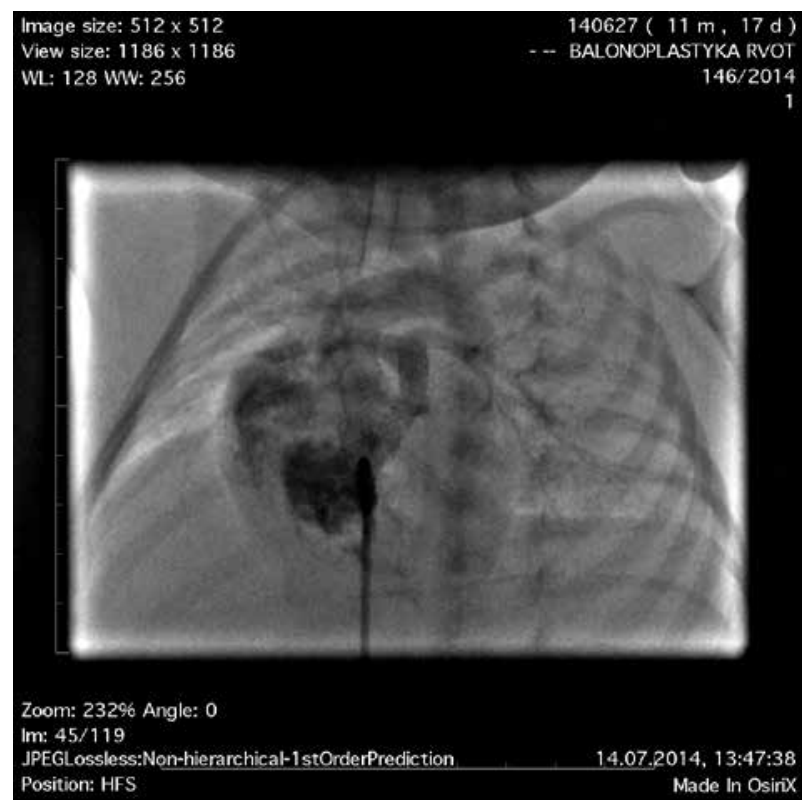

Figure 1. Control exit angiography after implantation of 2 vascular stents in the RVOT and MPA following telescope stent-in-stent technique (Abbott Vascular MULTI-LINK $4 \times 8 \mathrm{~mm}$ and $3.5 \times 15 \mathrm{~mm}$ )
MPA, and an evident increase of both pulmonary arteries' (LPA and RPA) diameters were obtained (Figure 2). The efforts to re-dilate RVOT stents were unsuccessful; therefore the $4.32 \mathrm{~kg}$ bw infant with observed $70-75 \%$ peripheral saturation was referred for a right modified BT shunt, which was made with implantation of a $4.5 \mathrm{~mm}$ Gore-Tex tube.

Regular follow-ups were performed until the age of 7 months. Antegrade flow to pulmonary artery blood flow velocity up to $4 \mathrm{~mm} / \mathrm{s}$ with mild recurrent diastolic wave from MPA to RV was confirmed. Her peripheral saturations were oscillating over $80 \%$ with short-term drops at the time of oral feeding, and viral infections. The child was chronically treated for recurrent urinary tract infections with prolonged antibiotic therapy; thus her weight gain was still less than expected.

Percutaneous balloon RVOT stent redilatation was performed at the age of 7 months. Control angiography performed to prior scheduled surgery proved correct localization of implanted stents with normally developed pulmonary arteries, with a current McGoon index value of 2.7. Finally at the age of 10 months and $5.7 \mathrm{~kg}$ bw, the girl was referred for surgical DORV correction with removal of implanted stents.

The procedure was performed via median sternotomy. The agenesia of the thymus gland and the hypoplastic MPA with the presence of palpable stents within the pulmonary trunk were exposed. There was clear evidence of macroscopically visible specific pericardial inflammatory reaction around the area of the stented MPA.

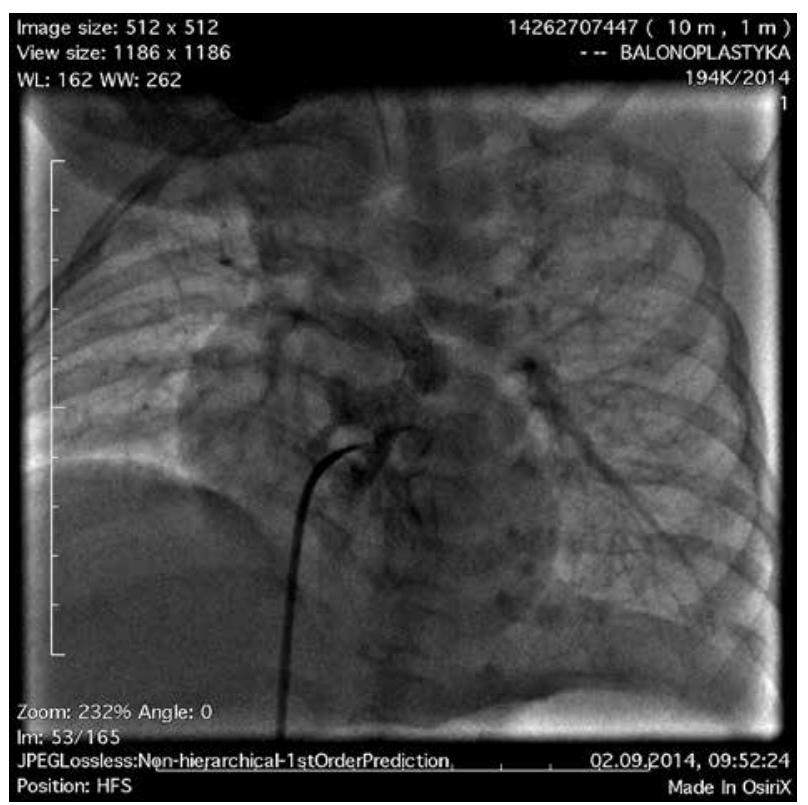

Figure 2. At 2.5 months of life diagnostic angiocardiography was performed: right ventricle hypertrophy and present RVOT-MPA blood flow and marked increase of the right and left pulmonary artery diameter were noted 
Classic cardiopulmonary bypass was commenced routinely. At $28^{\circ} \mathrm{C}$ central temperature the heart was stopped, and after opening the right atrium a large "malalignment" ventricular septal defect (VSD) was identified. The aortic valve was completely overriding the $15 \mathrm{~mm}$-wide VSD, while there was both subpulmonary and subaortic muscular conus in the right ventricle. The outflow from the severely hypertrophied RV to the MPA was secured with the stents protruding the right ventricle cavity. The free wall of the right ventricle was opened. The stents were dissected from fibrous inflammatory-like tissue and removed, and the obstruction of the RVOT was extensively resected (Figure 3). The "malalignment" VSD was closed using a large Gore-Tex (ML Gore and Associates, EU) patch with running monofilament suture. The RVOT and MPA were supplemented with a Contegra "mono-cusp" xenograft (Contegra, Medtronic, EU). The patient was weaned from CPB with sinus rhythm. In the early post-operative course, periodic arrhythmias of unexplained etiology were observed. Further recovery was uneventful.

In consecutively performed follow-up TTE, wide right ventricle outflow tract, unrestricted blood flow from RV to MPA and an extensive patch covering the VSD with the unobstructed left ventricle outflow tract were regularly observed. The present follow-up time is 14 months. The girl undergoes regular outpatient follow-ups in the local pediatric cardiology center.

\section{Discussion}

Double outlet right ventricle morphology occurs if the both subarterial conal walls (sub-aortic and sub-pulmonary) undergo simultaneous growth and expansion. In the pathology a sub-aortic conus never leads to natural resorption, with forthcoming semilunar-atrioventricular fibrous discontinuity $[1,2]$. Double outlet right ventricle can manifest with different anatomical variants. The clinical course of newborn patients suffering from DORV is related to mixed hemodynamics and pulmonary blood flow [3]. Right ventricle outflow tract obstruction or the opposite, unrestricted free pulmonary inflow, determines possible cyanosis, or congestive heart insufficiency symptoms. Stenosis of RVOT and underdevelopment of pulmonary arteries are anatomical conditions for severe cyanosis.

The traditional treatment strategy for newborns with DORV and critical right ventricle outlet obstruction (RVOTO) and various degrees of underdevelopment of pulmonary arteries presenting with severe cyanosis is the surgically modified systemic-to-pulmonary Blalock-Taussig shunt [1]. The procedure secures calibrated pulmonary blood flow and thereby proper oxygen saturation. This approach stimulates pulmonary circulation artery growth [1] and allows for terminating PGE1 infusion. Nevertheless, this procedure does not protect

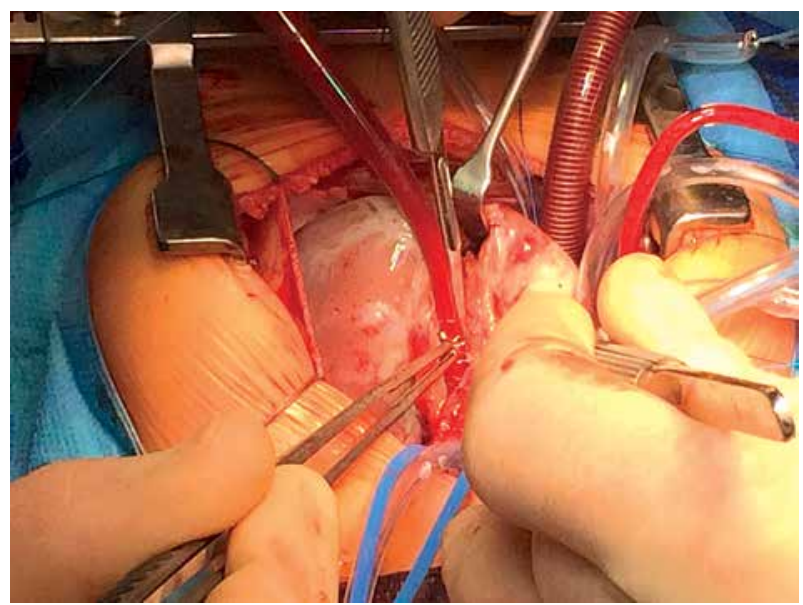

Figure 3. View at the operation: opened free wall of the right ventricle and main pulmonary artery, from the level of the RVOT up to the bifurcation of the MPA 2 stents, were dissected from the inflammatory tissue and removed. The obstruction of the RVOT was resected

against ongoing increase of the obstruction in the RVOT. The mechanisms of RV overload and pathological RV muscle overgrowth stimulation are continued, causing severe hypertrophy that may lead to disadvantageous closure of the RVOT, called "acquired" pulmonary atresia [4].

The case of our patient shows how difficult and complicated the medical history and pathophysiology of DORV with concomitant right ventricle outflow tract obstruction, pulmonary valve stenosis and hypoplasia of the main pulmonary artery can be. An important factor in the initially planned strategy was the very low body weight (hypotrophic, term born girl $2.3 \mathrm{~kg}$ ), presenting with critical cyanosis and an extremely poor pulmonary arterial bed despite PGE1 infusion.

The use of balloon angioplasty and stenting of the RVOT in the early neonatal period (in the case of our patient, the first percutaneous procedure was performed on the $4^{\text {th }}$ day of life), in the face of the unfavorable initial McGoon index, increased peripheral oxygen saturation [5]. In further observation initially maintained patency of the RVOT needed to be secured with RVOT stents ( $3^{\text {rd }}$ week of life), which enabled further growth of the pulmonary bed area $[6,7]$. Thus, the hypotrophic baby gained adequate weight with protection from severe cyanosis, hypoxemic spells and its potential complications, mainly cerebral hypoxia [6-8].

The increase of pulmonary artery diameters and corresponding McGoon index (increase of about 237.5\%) ensured the anatomical correction at the age of 10 months. The stents were successfully removed from the RVOT area, although there were no anatomical conditions to reconstruct the native pulmonary valve with the need to reconstruct the RV outflow with a valved xenograft. Probably the initial critical stenosis and underdevelopment of 
the pulmonary annulus precluded the option to maintain the native PV that was presented in more favorable anatomy by our colleagues [8]. Undoubtedly the approach created better conditions for anatomical correction in infancy, with improved peripheral oxygen saturation, the increase of pulmonary vasculature and adequate weight gained prior to the surgery [5-8].

The presented strategy, despite the technical limitations defined by low body weight, appeared safe and effective for the presented hypotrophic baby with DORV. Our promising experience encourages us to follow the treatment in further borderline cases of cyanotic newborns.

\section{Conclusions}

The procedure of RVOT stenting was found to be safe and effective in a hypotrophic child with DORV, concomitant severe RVOTO and hypoplasia of the pulmonary arteries. The procedure protected our patient against uncontrolled remodeling of the right ventricle and unfavorable evolution to "acquired" pulmonary atresia. This approach, RVOT stenting and subsequent BT shunt, allowed pulmonary vascular bed development and performance of successful anatomical correction in the $10^{\text {th }}$ month of life.

\section{Conflict of interest}

The authors declare no conflict of interest.

\section{References}

1. Skalski J, Religa Z (eds.). Kardiochirurgia dziecięca. Wydawnictwo Naukowe "Śląsk", Katowice 2003.

2. Karolczak M (eds.). Wykłady o sercu i kardiochirurgii wad wrodzonych. Czelej, Lublin 2008.

3. Van Praagh R. The cardiovascular keys to air - breathing and permanent land - living in vertebrates: the normal human embryonic aortic switch procedure produced by complete right left asymmetry in the development of the subarterial conal free walls, and the evolution of the right ventricular sinus. Kardiochir Torakochir Pol 2011; 8: 1-22.

4. Frater RW, Rudolph AM, Hoffman JI. Acquired pulmonary atresia in tetralogy of Fallot with a functioning Blalock-Taussig shunt. Thorax 1966; 21: 457-8.

5. Dohlen G, Chaturvedi RR, Benson LN, et al. Stenting of the right ventricular outflow tract in the symptomatic infant with tetralogy of Fallot. Heart 2009; 95: 142-7.

6. Shenoy AR, Padmakumar P, Subashchandra V. Right ventricular outflow tract stenting in tetralogy of Fallot with restrictive ventricular septal defect. J Invasive Cardiol 2006; 18: 59-60.

7. Dryzek P, Mazurek-Kula A, Moszura T, et al. Right ventricle outflow tract stenting as a method of palliative treatment of severe tetralogy of Fallot. Cardiol J 2008; 15: 376-9.

8. Dryzek P, Moszura T, Góreczny S, et al. Stenting of the right ventricular outflow tract in a symptomatic newborn with tetralogy of Fallot. Postep Kardiol Inter 2015; 11: 44-7. 